\title{
Mielopatía compresiva asociada al síndrome de Klippel Feil
}

\author{
Compressive myelopathy associated \\ with Klippel Feil syndrome
}

\section{Ronal Fredy Cerón, Julián Darío Ñáñez Paz • Popayán (Colombia)}

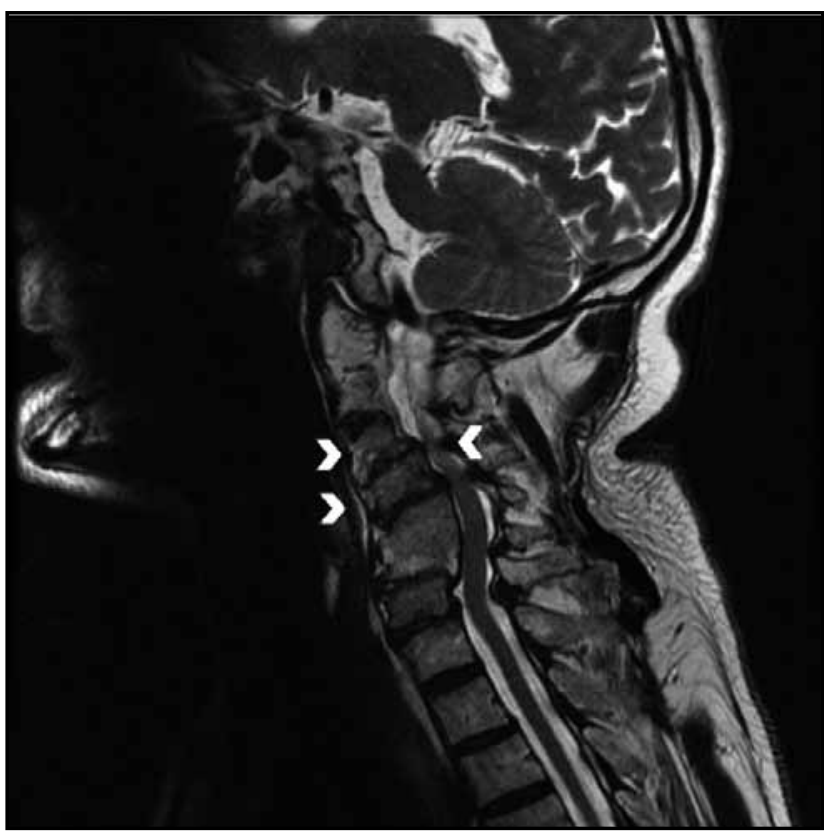

Figura 1. Se observa cuello corto, fusión de C5 y C6 asociado a retrolistesis con hipertrofia de las articulaciones interfacetarias, osteocondrosis, osteoporosis y colapso de la grasa peri-radicular. Los signos descritos se asocian a compresión medular (ver flechas).

Paciente género masculino, 78 años, con antecedentes de hipertensión arterial, enfermedad coronaria y cervicalgia crónica. Ingresa por cuatro horas de evolución consistente en cuadriparesia y parestesias difusas. Al examen físico impresiona cuello corto, pérdida de la lordosis fisiológica e hiporeflexia generalizada. La resonancia magnética revela fusión de los cuerpos vertebrales C5-C6, C6-C7 con retrolistesis grado I de C7-T1 asociada a canal estrecho. Requiere artrodesis anterior en dos ocasiones con mejoría amplia.

El síndrome de Klippel Feil (SKF), consiste en la fusión congénita de dos o más vértebras cervicales, secundaria a una segmentación defectuosa entre la tercera y octava semana de la embriogénesis $(1,2)$. Su transmisión es autosómica dominante con penetrancia reducida y expresión variable (1). La triada clásica de cuello corto, implantación occipital baja del cabello y limitación de la movilidad cervical, está presente en menos del $50 \%$ de los casos (3). Las alteraciones anatómicas degeneran en la estenosis del canal cervical asociándose a síndromes me-

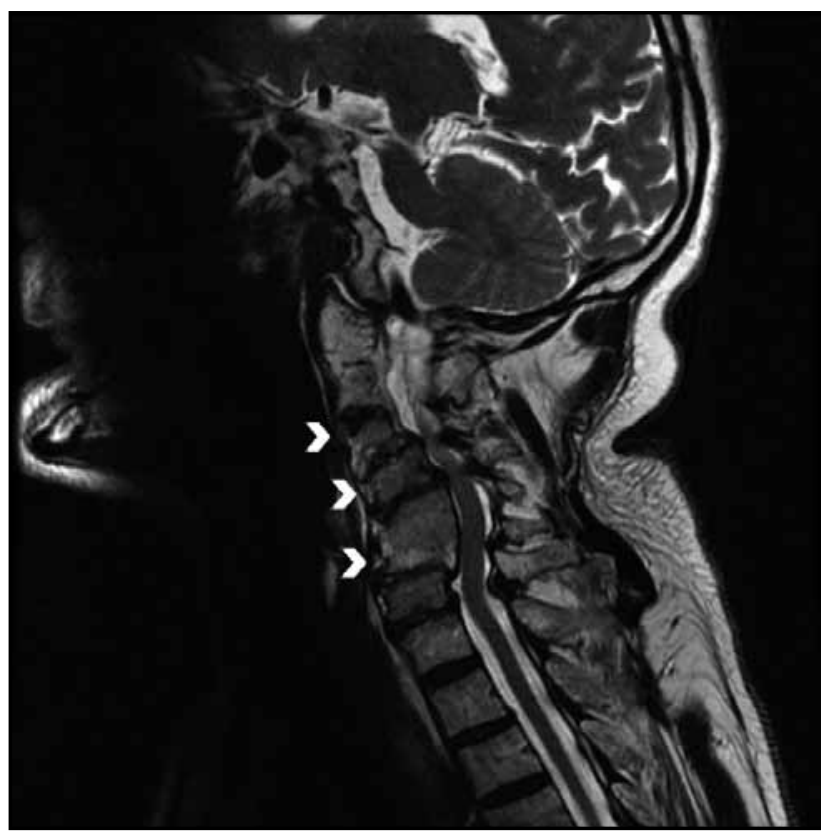

Figura 2. Retrolistesis grado I C4-C5 y C5-C6 asociado a colapso de los discos intervetebrales $\mathrm{C3}-\mathrm{C4}, \mathrm{C4}-\mathrm{C} 5$, $\mathrm{C} 5-\mathrm{C6}$ y $\mathrm{C6}-\mathrm{C}$.

dulares transitorios, tetraplejia e incluso subluxaciones fatales con traumatismos leves (4). El SKF se asocia a otros trastornos tales como la siringomielia, espina bífida, malformación de Arnold-Chiari, anomalías esqueléticas, renales, cardiacas, hipoacusia y sincinesias $(4,5)$.

\section{Referencias}

1. Palacios Martínez D, Díaz Alonso RA, Gutiérrez López M, Gordillo López FJ Síndrome de Klippel-Feil, una cervicalgia poco frecuente. SEMERGEN-Medicina de Familia. 2013;39(8):e63-e7.

2. Kaplan KM, Spivak JM, Bendo JA. Embryology of the spine and associated congenital abnormalities. The spine journal : offi $j$ North Ame Spine Soci. 2005;5(5):564-76

3. Samartzis D, Kalluri P, Herman J, Lubicky JP, Shen FH. "Clinical triad" findings in pediatric Klippel-Feil patients. Scoli Spinal Disor. 2016;11:15.

4. Smith BA, Griffin C. Klippel-Feil syndrome. Annals emerg med. 1992;21(7):876-9.

5. Balachandran G. Klippel-Feil syndrome and anterior cervical meningomyelocele: a rare case report. AJNR Amer j neurorad. 2009;30(9):E130.

Dr. Ronal Fredy Ceron Ortega: Médico general. Hospital universitario San José, Facultad de Medicina, Universidad del Cauca; Dr. Julián Darío Náñez Paz: Especialista Medicina Interna, Hospital universitario San José, Facultad de Medicina, Universidad del Cauca. Popayán (Colombia).

Correspondencia: Dr. Julián Darío Ñañez, Popayán (Colombia). E-mail: 1981joules@gmail.com Recibido: 23/VI/2017 Aceptado: 25/VI/2018 